project demonstrates tremendous capacity building needs in grassroots workers in the country. Further study is needed to evaluate whether this increased knowledge results in changes in practice for influencing child violence policy in Pakistan.

\title{
0225 USING EVIDENCE TO INFLUENCE CHILD HEALTH POLICIES: A PILOT PROGRAM IN PAKISTAN
}

P Puvanachandra*, A Chandran, S Sarfraz, T Akhtar, A A Hyder Correspondence: Johns Hopkins Bloomberg School of Public Health, E5038, 615 N. Wolfe Street, Baltimore, MD 21205, USA

10.1136/ip.2010.029215.225

Introduction Reported annual rates of violence against Pakistani children are 1.57-3.18 per 100000 . NonGovernmental Organisations (NGOs) can be powerful resources in treatment and advocacy for child violence. There are no training programs within Pakistan regarding using data for effective advocacy against child violence.

Methods Employees of NGOs focused on child violence were invited to a training focused on utilising evidence for influencing policy. Training in data collection, monitoring/ evaluation, accessing literature and cost-benefit analysis was given in collaboration by Johns Hopkins Bloomberg School of Public Health, USA and Fatima Memorial System, Pakistan. Knowledge assessments were given before and after workshop participation, and a knowledge retention survey was given 4-8 weeks later.

Results 35 individuals were trained; two-thirds were female. Post-training tests showed that (compared with prior), $90 \%$ could name two components of the advocacy cycle (vs $30 \%$ ), $75 \%$ could differentiate incidence and prevalence (vs $0 \%$ ), $60 \%$ could identify two literature databases (vs 10\%), 90\% could identify advantages and disadvantages of qualitative research (vs $40 \%$ ), and $65 \%$ could differentiate qualitative and quantitative research (vs $40 \%$ ). The retention survey revealed that $50-65 \%$ recalled basic characteristics of surveillance, quantitative/qualitative research, and database access.

Discussion NGO workers demonstrated a significant increase in knowledge following training on utilizing evidence. This 